\title{
HUMAN 4.0: NEXT ERA IMPORTANT SKILLS FOR EMPLOYMENT IN THAILAND
}

\author{
Irina V. Onyusheva \\ Turan University, Almaty, Kazakhstan \\ Stamford International University, Bangkok, Thailand \\ Nopbhol Naruenatdumrong
}

Stamford International University, Bangkok, Thailand

The next era or 4.0 age are frequent buzzwords today. Human potential and human skills are the key to invention of new things through new knowledge generation and having great impact on the whole society at the end. People are increasingly concerned with their living and working in the time of big changes that require appropriate change management skills and overall flexibility. It is not easy to adapt to all of the global upcoming changes. Exploring the issue of how people adapt to these quick changes and thus change themselves gives us an opportunity to understand and develop future HR competitive strategy. In this paper the authors discuss the specificity of the next-generation jobs and the variety of skills needed for them. Comparative analysis carried out among ASEAN countries is presented. It takes into consideration not only the proximity of these countries' location in relation to each other but also the peculiar factors of their economic development.

Keywords: next generation professionals; human skills; the 4.0 era; human capital; Thailand; ASEAN

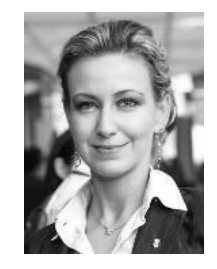

STAMFORD U"NIVIEAR SIITYY SIGNATURE M.B.A
Irina Onyusheva

Dr., Prof., Turan University, Almaty, Kazakhstan; Stamford International University, Bangkok, Thailand Interests - Economics, Strategic Management, Formation, ensuring and increasing economic competitiveness on both micro- and macro- levels; Human Capital development; HR Management; Knowledge Economy; Knowledge Management; Project Management; Management in Education

E-mail: dr.irina.onyusheva@gmail.com

\footnotetext{
Nopbhol Naruenatdumrong

Stamford International University, Bangkok, Thailand, International MBA Program Interests - International Business Management, Strategic Management, HR Management

E-mail: nopbhol.naruenatdumrong@gmail.com
} 
Living under today's social and economic conditions of the ongoing globalization requires, in the first place, readiness to changes and the ability of quick adaptation. It would be logical to suggest that these trends have also found their reflection and great impact on labor force needs, labor content and work organization in general. Human skills' development today is constantly adding value to a variety of industrial value chains across nearly all economic sectors.

This may not only have consequences for low-skilled workers and their operational shop floor activities, but also for high-skilled white collars and even top management representatives. On the top of that, particularly in Germany, with its comparatively large industrial base, representing $22 \%$ of the gross domestic product, such implications were emphasized on many times; see, for example (Bonekamp, 2017).

In view of this situation, this article firstly provides an overview of the current discussion on the consequences from development of the Industry 4.0 on the state of labor and its content, HR skills and work organization in general.

Let's start with a brief overview of the humans and their most vital sets of skills by historic eras. This will later help us formulate the skills necessary for a new, upcoming era.

The Era 1.0 is also known as the age of agriculture. The absolute majority of people during those times were farmers, gardeners etc. The 1.0 idea of career was quite plain: the man/woman was doing any job to survive. This is what people do in a situation of extreme hardship, political upheaval, or under specific socioeconomic conditions that limit their opportunities and choices. That probably describes the situation for the huge masses of people throughout most of the humankind history. This state of affairs, unfortunately, still exists today, especially among those who have been hardest hit by recessions and hardcore poverty. In these situations, the only meaning of "success» (Linda, 2015) would be able to earn enough to survive. The conflicts that people experience within "the 1.0 career" often include the impacts of poor working conditions, racial, social and/or religious discrimination, and limited opportunities for even getting onto a career path that might lead to something better. People who are still living under the 1.0 ers, usually have no complex skills and only basic technical knowledge is usually completely enough for them.

In the era 2.0, changed economic and political environment started to support more modern occupations, including the so-called "with-collar jobs" (Gyorgy, 2012). The absolute majority of such jobs were located within large organization which started to quickly develop since the early $20^{\text {th }}$ century. This was also the start of hierarchies' formation in business organizations. This kind of jobs were already able to provide more or less predefined career paths, and also such jobs within hierarchical business organizations became much more available to all the people who were capable to do them. The career path also became facilitated by new educational opportunities and social class advantages people brought with them. Career during this era often came along with the notion of "careerism". During those times it meant pursuing authority line, more power, money and higher position inside an organization. Another important indicator of performance became KPI -- Key Performance Indicator (TGI's role in Thailand 4.0 era, 2017). This career culture has already become traditional and in so many cases it begins conditioning us since the early childhood. Skills required for this era included: managing ability, paperwork administration, communication and coaching skills. In simple terms, these skills cover everything that concerns dealing with people. 


\section{HUMAN 4.0: NEXT ERA IMPORTANT SKILLS FOR EMPLOYMENT}

In the era 3.0 one of the relevant issues became balancing between personal life and work (professional life). Opposite to 2.0 which was more stick to the office, the 3.0 era has become more relaxing, thus, staff has less stress now. Arrival of the 2.0 era coincided with the beginning of the technology and communication age, and both started to impact our life styles and our work style significantly. Remote working concept became realistic and workable during those times. The key benefit from technologies' development for all office workers was much greater flexibility in modes of work and in the working schedule too. Introduction of the Internet was another significant achievement. It symbolized the beginning of the information sharing era. With the development of the Internet, people were also introduced to social networking and Facebook in the first place.

At the dawn of the 4.0 era, many new job functionalities became motivated by the sense of service and also sense of connection with larger groups of people. Social media quickly became part of people's everyday life, thus, today human community is huge as never before. Any situation taking place in one part of the world can become talk on the opposite side of the world within seconds. Therefore, people get vast opportunities to impact human lives with the lightning speed.

This is the future, and many of us are already feeling the pull towards the 4.0 career. And even if you're not, you need to know how to work with those who are already in. For example, we already know that today's workplace requires high level of collaboration with very diverse people. You need to align your talents and skills with common objectives, no matter what you are working on -- a product or a service. This automatically means diminishing your ego, learning to "forget yourself" in the course of servicing teamwork towards a larger purpose, while also constantly looking for opportunities for learning, growth and having impac. From the 4.0 perspective, you move away through self interest, not getting closer to it. Now you are tuned into to a larger picture, in which you're one player finding his/her ways to make a positive contribution to the service or the product. This includes being aware of how you are perceived by others.

Consistent with the above, "the 4.0 careerist wants to work for a company that practices and values positive leadership, transparency, informality, collaboration, high ethical standards, innovation and is also a fun place to work" (TGI's role in Thailand 4.0 era, 2017). They want companies that promote and value diversity and also have an equitable reward system for employee achievement. Inside such companies, people work hard but also have fun.

The 4.0 career is especially visible when people state they want to contribute to the common good which can be often through the value and the usefulness of a product or a service. That theme links the 4.0 career with the emerging new business model focused on creating sustainable enterprises and the "triple bottom line" - financial, social and environmental measures of success. It combines financial success with contributing to social needs and problems. This is also known as "social entrepreneurialism" (TGI's role in Thailand 4.0 era, 2017) - the movement towards creating successful businesses that also contribute to the solution of social problems. In effect, the 4.0 careerist thinks of work as a vehicle for change and influence upon the larger community (TGI's role in Thailand 4.0 eras, 2017). 


\section{The next generation of expectations for the 4.0 society and its working environment} in particular look roughly as follows:

- All work processes and operations will be monitored and controlled by the increasingly intelligent machines and fewer human workers will be directly involved in management and control;

- Drawing upon advanced artificial intelligence algorithms and vast quantities of realtime big data, these machines will select strategies, tailor offerings and tactics and then monitor their fulfillment, again, all without human intervention;

- Many industrial factories will be also run by means of remote control;

- The growing share of deliveries will be facilitated by driverless cars and trucks as well as drones;

- In a nod to some of the best science fiction stories, problems will be resolved before they happen based on complicated predictive analytics engines drawing real-time input from a vast array of billions of sensors;

- Communication technologies continue to advance to enable high-quality, real-time engagement with distributed teams and communities all over the planet;

- The currently unfulfilled promise of big data will increasingly be realized as organizations learn to wrestle this beast with newer technologies, smarter algorithms, as they also learn how to treat this data as a strategic life force;

- Routine work will increasingly be automated freeing up positions, time and bandwidth for all workers;

- Innovations will occur in an open-source style within the communities solving problems and sharing ideas and feedback with each other;

- Projects will be recognized as the engines of creation and project management practices will expand to take advantage of the new tools for communication, monitoring, reporting and collaboration. Routine work of monitoring discrete tasks will be automated, and project team members as well as project managers will be free to focus on problemsolving and other, more creative activities;

- The promise of virtual teams will finally be realized based on the advancements in communication technologies;

- Decision-making will be increasingly data-driven, most of routine decisions will be handled by machines;

- Organizations will flatten and spread horizontally, their advancement will be based more on the ability to contribute value and less on the ability to do more at a higher level;

- Managers will coach, support and facilitate, but not oversee day-to-day work of their subordinates;

- There will be fewer managers overall due to the growth of process automation across all sectors.

\section{Challenges for Thailand in the 4.0 age}

The first and the greatest challenge is the relatively aging society: in about 8 years from now Thailand is predicted to join the group of countries with the most aging societies as the birth rate is steadily decreasing. In the long term this means that firms may lack professional staff, and for this reason, some businesses and politicians are already considering extending the retirement age or think over the strategy of rehiring retired staff. 


\section{HUMAN 4.0: NEXT ERA IMPORTANT SKILLS FOR EMPLOYMENT}

Industries of the 4.0 era will be transformed in the direction of creativity production. The ability to produce becomes less important, while the factor of having creative skills along with out of box thinking style seem to become vital.

Rapid information inflows and outflows. When something happens in one country/region, it can impact the society and the people on the other side of the world. Thus, both firms and people must be ready for changes becoming more rapid as never (World Economic Forum, 2016).

Table 1 - Human Skill Profiles within ASEAN Countries

(Source: Compiled by the authors on the basis of The Global Human Capital Report, 2015-2018)

\begin{tabular}{|c|c|c|c|c|c|c|c|c|c|}
\hline Country & 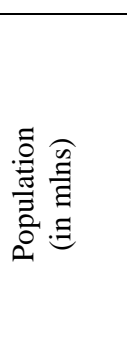 & 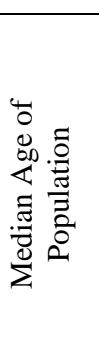 & 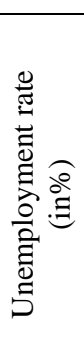 & 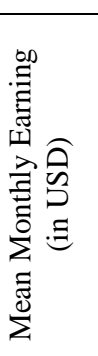 & 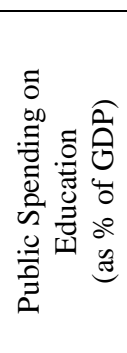 & 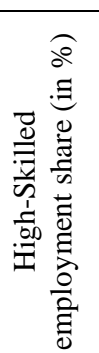 & 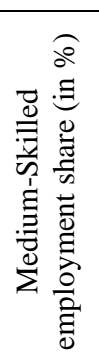 & 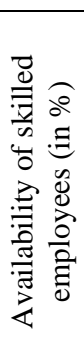 & 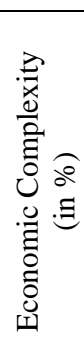 \\
\hline Thailand & 68.864 & 37.8 & 0.2 & 1,089 & 4.1 & 14 & 90 & 47.7 & 65.7 \\
\hline Myanmar & 52.885 & 27.7 & 0.8 & - & 1.2 & 21.3 & 87.9 & 29.9 & - \\
\hline Cambodia & 15.762 & 23.9 & 0.2 & - & 1.9 & 3.8 & 82.8 & 39.7 & 39.2 \\
\hline Singapore & 5.662 & 40.0 & 1.8 & - & 2.9 & 56.2 & 92.3 & 68.3 & 73.3 \\
\hline Brunei & 423.000 & 30.0 & 7.0 & - & 4.4 & 40.8 & 86.0 & 48.7 & - \\
\hline Philippines & 103.320 & 24.1 & 5.5 & - & 2.7 & 24.1 & 68.4 & 59.0 & 57.7 \\
\hline Vietnam & 94.569 & 30.4 & 2.1 & 611 & 5.7 & 10.8 & 60.1 & 47.6 & 48.5 \\
\hline Lao PDR & 6.758 & 22.7 & 0.7 & - & 3.3 & 5.1 & 98.9 & 48.2 & 28.1 \\
\hline Malaysia & 31.187 & 27.7 & 3.5 & 1,633 & 5.0 & 25.5 & 86.2 & 71.9 & 64.5 \\
\hline Indonesia & 261.115 & 28.0 & 5.5 & 511 & 3.6 & 9.9 & 81.9 & 59.5 & 49.5 \\
\hline
\end{tabular}

More of online working: the Internet becomes an important facility in everyday life. Working or living within digital space become common, everyday practice. It can, inter alia, help increase work efficiency of staff in any sort of organizations, across all sectors.

Smart life with smartphones: smartphones become an important element of people's everyday life and lifestyle. The growing role of mobile devices is basically unavoidable already.

Personal and working life become one - people of the 4.0 era will not divide between personal life and working life all that strictly as it used to be. This changed lifestyle has already its own name -- "Weisure Time" (Gyorgy, 2012), that is, Work + Leisure. Thanks to digital technologies people can work anytime and from anywhere on the planet. 
Sharing society: Intensive social networking makes idea-sharing much easier. Organization can easily apply the very concept of social networking to their functioning. This can help firms create their own, unique sharing culture.

E-learning during the 4.0 era - new generation of learning sources provides easier and quicker access to the teaching systems, from anywhere and anytime. Electronic books gradually take over standard paper cover books, while increasing volumes of knowledge, patents and know-hows can be found easily online, without any sort of boundary in access and/or further use.

More of social sustainability: new businesses not only concentrate on their profits like most of businesses did in the past but they are also concerned about their social impact, widely known as corporate social responsibility.

In this paper we focus only on the ASEAN countries, their key statistics are presented in Tab. 1.

Tab. 1 presents the human skills' profiles in the context of the ASEAN countries. According to the data of the Global Human Capital Report as of 2018, Thailand has highly skilled people, the share in the overall population of this country is roughly around 14\%, while in such a developed country as Singapore the share of the same reaches $56.2 \%$ and in Brunei it is about 40\%, while in Malaysia it is about 25\% (World Economic Forum, 2017). However, Thailand has the largest in the ASEAN share of the medium-skilled employees at the same time. This means that if some people in the latter group would be able to convert to high-skilled staff, the average income earnings and the share of highly skilled employees will also automatically increase.

Based on the needs skilled in 4.0 era, the recommendation for Thai labor to increase their skill to maximize their wages as well. Thank you to technology which cause of rapid change of the world. Hence, more and more routine tasks will be fulfilled by machines or the so-called smart machine since automatic work is significantly cheaper as compared to human one. There are four areas that require increased attention in the course of next-generation jobs' development.

1. Technical agility skill: Even formerly creative jobs such as marketing, for example, are increasingly overwhelmed by quantitative-based technologies. There is no way to avoid technology in so many spheres and sectors these days. On the contrary, taking the opportunity from new technologies may help in gaining more benefits. Thanks to the Internet today it is quite possible to get trained according to the latest programs and master the most advanced and sophisticated applications, thus staying tuned. If you fail to keep yourself updated, technologically in the first place, you will be moving backward at the speed of change while the new generation will keep moving forward, and quicker than ever before.

2. Data Agility: Highly skilled employees can operate using their gut instinct mostly and prefer their own experience to gathering data. Analyzing skill is also important to a new era manager although computers and machines can perform this function much better. By the way, using data for making decisions is not only about accuracy of calculations but also about instinct and previous experience. And all of these cannot be attributed to machines right now.

3. Project Agility: As it has been already mentioned earlier, routine tasks will be increasingly automated thanks to machines and artificial intelligence (AI). The important role of a project manager or a project sponsor here is understanding how to fulfill the project overall and support all the team members involved in it. 


\section{HUMAN 4.0: NEXT ERA IMPORTANT SKILLS FOR EMPLOYMENT}

4. Networking Agility: Many organizations focus on horizontal approach instead of vertical one. Highly skilled staff will possibly often be called upon to organize temporary coalitions to seize emerging opportunities or fight/prevent fast-moving threats. A highly efficient connection can help tapping into the right resource at a right time.

Thai government has already announced and presented their vision of Thailand 4.0 the key aim of which is to transform the country into a developed economy. However, developing people populating the country surely comes first, as the top priority. Pressure imposed by the new era of automation and smart machines might lead to replacement of the many among current employees due to the need for radical cost reduction. Hence, challenges described and analyzed in this article are faced today not only by the citizens of Thailand but also in many other places around the globe.

\section{References:}

Bonekamp L. et al. (2017). Consequences of Industry 4.0 on Human Labour and Work Organisation. Journal of Business and Media Psychology. Cologne: Hochschule Fresenius University of Applied Sciences. Available at: http://journal-bmp.de (Accessed 22.08.2019).

Cowan, A. (2017). The Industrial Age, Agricultural Age and Information Age, available at: https://prezi.com/xq9axj4w6-7g/the-industrial-age-agricultural-age-and-information-age

Romero, D. et al. (2018). The Operator 4.0: Human Cyber-Physical Systems and Adaptive Automation towards Human-Automation Symbiosis Work Systems. Sweden: Chalmers University of Technology.

Szilagui, G. (2017). One Hundred Years of Management. Budapest: Corvinus University of Budapest.

Kenney, J.Z. (2018). The Next Phase in the Digital Revolution: Intelligent Tools, Platforms, Growth, Employment. Communications of the ACM, 6 (2). 54-63.

TGI's role in Thailand 4.0 era. (2017). Available at: https://www.bangkokpost.com/business/ news/1351799/tgis-role-in-thailand-4-0-era.

Official Website of the World Economic Forum. The Future of Jobs and Skills, Available at: http://reports.weforum.org/future-of-jobs-2018 (Accessed 22.08.2019).

The Global Human Capital Report for 2015-2018. World Economic Forum, available at: http://reports.weforum.org/future-of-jobs-2018 (Accessed 22.08.2019).

Paper submitted

Paper accepted for publishing

Paper published online
14 November 2018

21 January 2019

31 March 2019 